\title{
Artigos
}

Kiran Asher

Clark University

\section{Engendrando desenvolvimento e etnicidade nas terras baixas do Pacífico colombiano}

Resumo: Neste ensaio, exploro como as organizações e redes de mulheres afro-colombianas moldam e são moldadas por iniciativas do Estado para desenvolver e modernizar a região do Pacífico. Argumento que, agindo assim, elas mobilizam e vão além da retórica desenvolvimentista do Estado e do discurso de uma etnia negra 'gendrada' e da tradição das organizações políticas negras da região.

Palavras-chove: mulheres afro-colombianas, estratégias de desenvolvimento, políticas étnicas e de gênero.

Copyright (c) 2004 by Revista Estudos Feministas

* Excepcionalmente neste artigo, as notas estão editadas ao final do texto.
O Litoral Pacífico da Colômbia, ou a região Choco, é uma área rica em recursos naturais, que se estende do extremo sul do Panamá ao extremo norte do Equador, ao longo da costa do Pacífico. Em 1991, a Colômbia adotou uma nova Constituição que inclui leis e políticas com implicações contraditórias para a região do Pacífico e seus/ suas habitantes. Por um lado, a Lei 70, de 1993, baseada no Artigo Provisório 55 da Constituição de 1991, reconhece os/as afro-colombianos/as (que compõem $90 \%$ da população da região) como um grupo étnico separado, com direitos a possuir terras coletivamente e utilizá-las dentro dos moldes tradicionais. ${ }^{1}$ Por outro lado, as reformas econômicas neoliberais esboçadas no 'Charter' de 1991 identificam áreas 'marginais', como as da região do Pacífico, para vários projetos de macrodesenvolvimento, com vistas a extrair seus recursos naturais e modernizá-las. Além disso, em consonância com os apelos da Constituição pela proteção do meio ambiente colombiano, as Terras Baixas 
elas se mobilizam e vão além da retórica desenvolvimentista do Estado e do discurso de uma etnia gendrada e da tradição dos movimentos sociais negros na região. Concluo discutindo como o ativismo das afro-colombianas complica a nossa compreensão de como operam as intervenções para o desenvolvimento. O ensaio mostra também como as subjetividades e o agenciamento das mulheres negras são moldados diferenciadamente, desigualmente e discursivamente pelas, e contra as, intervenções políticas e culturais na região.

\title{
Plan Pacífico: da "inércia do subdesenvolvimento" para "desenvolvimento sem sujeltos"?
}

\begin{abstract}
Um tráfico incessante de mercadorias e pessoas fluía ao longo do rio Atrato, em Quibdó (a capital do estado de Choco). Os prédios de gesso e cimento, delineando o malécon, rachavam e mofavam sob o intenso calor, com sua pintura, outrora brilhante, empolando e descascando na umidade do ar. Ao passar pelos vendedores, que compravam peças artesanais de ouro de mulheres e homens chocoanos, lembrei-me da vista aérea do rio Atrato enquanto voava para Quibdó. Contaminado com o mercúrio usado na mineração comercial, o rio Atrato parecia uma corda grossa e verde insinuando-se lentamente pela paisagem. Enquanto a mineração do ouro e de outros metais preciosos (juntamente com a extração da madeira e o comércio do marfim vegetal) tem sido a base da economia extrativa da região desde os tempos coloniais, a pesca, caça e a agropecuária são as principais atividades de subsistência das comunidades negras dos quatro estados do Litoral do Pacífico.
\end{abstract}

Refletindo sobre a situação da região durante uma visita a Quibdó nos anos 1980, Thomas Sanders, um exprofessor de Religião e membro do Universities Field Staff International, observou que "... o Choco continua a simbolizar um tipo de pobreza e de subdesenvolvimento em que cultura e raça têm influência". ${ }^{4}$ De acordo com Sanders, a região do Choco continuou a sofrer da mesma "inércia do subdesenvolvimento" que ele havia testemunhado durante sua primeira visita em 1970, apesar do aumento do preço do ouro no mundo. Para Sanders, o futuro da região residia no exercício do poder político e da responsabilidade econômica para desenvolver os ricos recursos naturais e humanos e melhorar o padrão de vida. ${ }^{5}$

Mais de uma década depois, um relatório feito pelo Departamento Nacional de Planejamento (DNP) reflete o diagnóstico de Sanders, observando que "a pobreza é a 
coligados a uma política partidária formal, opõem-se a tais medidas modernizadoras. Janeth Rojas, uma feminista mestiça de Cali, com experiência em projetos de desenvolvimento a longo prazo na região do Pacífico, resume sucintamente as reações de muitos/as afrocolombianos/as:

Essa visão de desenvolvimento com respeito às comunidades negras baseia-se fundamentalmente em [a noção de] "ter" (TENER) mais do que na possibilidade de "ser" (SER). Com isso subentende-se que a melhoria de qualidade de vida é medida mais através da satisfação das necessidades básicas, melhores salários e aumento do consumo, do que do fortalecimento do direito de ser diferente. ${ }^{11}$

Talvez os mais notáveis críticos das iniciativas do Estado colombiano para o desenvolvimento sejam os membros de um grupo de intelectuais negros/as e ativistas que uniram forças coletivamente sob o nome de Processo de Comunidades Negras (PCN). ${ }^{12}$

Carlos Rosero, um antropólogo de Buenaventura e membro da liderança do PCN, rejeita a representação que - Estado faz da regiáo e do seu povo como "marginal e pobre". ${ }^{13}$ Ele argumenta que o Plan Pacífico foi concebido nos escritórios de planejamento do governo e é uma forma de "desenvolvimento sem sujeitos", porque ignora as percepções, necessidades e agenciamento dos/as afrocolombianos/as. ${ }^{14}$ Rosero e outros/as citam como evidência o fato de que as primeiras versões do Plan Pacífico enfocavam primordialmente planos de macrodesenvolvimento e investimento a fim de promover a atividade econômica na região. ${ }^{15}$ Eles/as corretamente mencionam que as questões sócio-culturais e ecológicas foram introduzidas na agenda desse plano inicial após muito lobby de grupos étnicos e de ONGs ambientalistas.

Refletindo a respeito da onda anterior de desenvolvimento no Pacífico, os/as críticos/as observam como tais projetos - planejados na capital andina e incompatíveis com as realidades sócio-culturais da região - foram malsucedidos e fizeram surgir ondas de migração em direção a cidades do Pacífico e além. ${ }^{16} \mathrm{~A}$ população rural deslocada, inclusive um grande número de mulheres, foi incorporada à economia monetária como mão-de-obra barata na agroindústria e na cultura aquática, o que levou a um colapso dos sistemas de subsistência locais e, geralmente, deixou as comunidades mais empobrecidas que antes. ${ }^{17}$ Betty Ruth Lozano ${ }^{18}$ observa que a intensificação dos sistemas de acumulação de capital levou a uma duplicação ou triplicação da carga de trabalho das mulheres e reforçou a subordinação de gênero das mulheres 
articula essa preocupação em termos coloquiais:

Pra que serve água potável, eletricidade, escolas, clínicas, aeroportos, reservas florestais, grandes empresas e dinheiro se temos vergonha de sermos negros, se denunciamos nossas fazendas e vendemos nossas terras, se nos acanhamos de comer o que tiramos da floresta, ou as nossas comidas tradicionais, e se nos esquecemos de como fazer uma catanga [uma armadilha para lagostas], se abandonamos o território que tem sido a nossa vida, se todo esse desenvolvimento traz violência e pobreza? Nossa busca principal agora é pelo direito a "ser" [SER] sem negar a importância de "ter" [TENER] condições materiais para gozar a vida como camponeses dignos, aqui nos nossos rios. $^{25}$

Em reuniões públicas, em negociações com o Estado, assim como em entrevistas e conversas, os/as ativistas do PCN chamam a atenção para as várias práticas de subsistência das comunidades negras - agricultura, pesca artesanal e caça, catação de mariscos, extração de vários produtos renováveis, como também extração de madeira e mineração em pequena escala. Observam que os/as afrocolombianos/as vivem na região desde o período colonial e desenvolveram esses sistemas de produção econômica ecologicamente sustentáveis baseados/as nas tradições africanas e ameríndias. Para os/as ativistas do PCN, são essas práticas 'ancestrais' e as relações sociais associadas a elas, baseadas no parentesco e nos laços de família, que representam o locus da etnia e da diferença dos negros, que devem ser o fulcro do "desenvolvimento culturalmente apropriado" na região. Leyla Arroyo, um outro membro ativo no PCN de Buenaventura, observa o seguinte:

Acredito que a identidade étnica está no centro do processo organizativo do povo negro. O reconhecimento das comunidades negras como um grupo étnico é uma de nossas maiores vitórias. Trabalhamos para que o nosso povo sinta orgulho de ser negro; reafirmamos quem nós somos, conquistamos auto-estima. [...] Acredito que podemos desenvolver uma visão de vida alternativa, um modelo econômico diferente, baseado nas nossas tradições, que seja justo e que inclua todos os aspectos da sociedade. ${ }^{26}$

Contudo, os/as afro-colombianos são marcados/as por muitas distinções regionais, ideológicas, de classe e de gênero. Dada essa heterogeneidade, os debates em torno do que significa ser 'negro/a' ou 'afro-colombiano/a' e o estágio incipiente das organizações negras em nível nacional, não existe uma visão comum ou politicamente viável de um "desenvolvimento culturalmente apropriado". Dentro deste contexto, os movimentos sociais de negros na 
observa que os primeiros planos de desenvolvimento para a região surgiram nas décadas de 1950 e 1960, durante o período de desenvolvimento do Terceiro Mundo pósSegunda Guerra Mundial. Uma série de desastres naturais na região (inclusive um incêndio em Quibdó em 1966 e um maremoto em Tumaco em 1979) também abriram espaço para grandes projetos de reconstrução apoiados pelo Estado. Nas décadas seguintes, vários eventos, instituições e práticas - evangelização, concessões para florestamento, estudos para avaliar o potencial agroindustrial, desenvolvimento de culturas aquáticas, projetos para a construção de portos e canais - levaram o desenvolvimento e integração da região ao interior do país. ${ }^{28}$

No final da década de 1960, projetos de desenvolvimento como o PLADEICOP (Projeto de Desenvolvimento Integrado para o Pacífico Colombiano), do presidente Belisario Betancur, tinham as mulheres como alvos de projetos de bem-estar social, contra a pobreza e de saúde rural. Essas iniciativas continuaram na forma de programas de assistência como o El Plan de Hogares de Bienestar (Plano para Casas de Bem-Estar), que era parte do plano sócio-econômico do presidente Virgilio Barcos para a região do Pacífico. ${ }^{29}$ Programas do convênio entre a Corporación Autônoma Regional Del Valle Del Cauca e a Holanda introduziram novas tecnologias e técnicas para a intensificação da produção agrícola em pequena escala na região. Embora esses programas produtivos não visassem às mulheres, como Lozano e Rojas demonstram, ${ }^{30}$ eles incorporaram com sucesso as mulheres negras ao processo de desenvolvimento. Por exemplo, na região de Tumaco, no Pacífico Sul, mulheres, em grande número, foram empregadas em pequenas tarefas em fazendas de camarão e em plantações de palmeiras para a extração de óleo, e integradas ao setor agroindustrial. Em 1988, um PLADEICOP mais abrangente lançou um projeto direcionado às mulheres para facilitar a contribuição delas ao setor produtivo. ${ }^{31}$ Esses projetos de desenvolvimento correspondiam à tendência internacional das abordagens Mulheres-no-Desenvolvimento (Women-in-Development) WID), que defendia a necessidade de integrar as mulheres ao processo de desenvolvimento e demonstrava que, além da contribuição ao bem-estar da família, as mulheres são uma parte importante do setor econômico produtivo e devem ter acesso igual aos seus benefícios. ${ }^{32}$

Como a pequena descrição no início desta seção indica, as mulheres negras são uma parte ativa e visível da economia da região. Na década de 1980, mulheres padeiras, costureiras, peixeiras, vendedoras de frutas em Guapi e Tumaco formavam pequenos grupos em torno de 
Desarollo de la Mujer de Buenaventura (FUNDEMUJER), era a maior das três cooperativas, consistindo de 25 grupos de mulheres, com um total de 800 membros. Com uma história organizacional e institucional estabelecida, as mulheres negras começaram a questionar, nas cooperativas, sobre suas identidades étnicas e de gênero, e procuraram ir além das atividades produtivas. ${ }^{36}$

Em abril de 1995, houve um encontro entre o CoopMujeres de Guapi com um novo programa para mulheres negras fundado pelo governo do Canadá e administrado pela Fundación FES, uma fundação privada colombiana. Os executores desse fundo colombianocanadense encontraram-se com membros das cooperativas para discutir suas propostas e planos para os anos seguintes. No encontro, Sylveria Rodríguez, a diretora do CoopMujeres, disse que os membros queriam direcionar novos fundos para o treinamento técnico das mulheres. Além disso, ela e membros da cooperativa queriam realizar oficinas sobre mecanismos de participação política, cidadania, relações interpessoais e familiares. Quando perguntada a respeito de oficinas sobre os direitos das mulheres, a resposta de Sylveria Rodríguez foi:

Já conhecemos os nossos direitos; agora queremos aprender como obter nossos direitos; ensinar a outras pessoas sobre os nossos direitos. Precisamos educar os nossos homens sobre os direitos das mulheres. No ano passado, comemoramos o Dia dos Pais no Coop Mujeres. Este ano, estamos tentando fazer com que cada membro "conquiste" o seu parceiro e o traga para a oficina.

No ano anterior, uma oficina sobre cozinha regional foi realizada paralelamente à comemoração do Dia dos Pais. Tal evento combinou atividades produtivas (cozinhar) com o resgate de tradições culinárias locais e exibiu as atividades dos membros das cooperativas para os pais e esposos presentes.

No dia seguinte ao encontro, Cipriana Diuza, uma professora e membro recente do CoopMujeres, contou-me que se engajou na cooperativa porque era "organizada, fundamentada, e ajudava ativamente mulheres solteiras, mães solteiras, mulheres pobres e chefes de famílias". Mas confessou ter curiosidade a respeito de "toda essa confusão em torno de ser mulher negra". Ela sentia que "nós somos mulheres negras, alegres, mas ainda escravizadas, ainda temerosas. Ainda precisamos aprender a valorizar o nosso dialeto, a nossa religião, as nossas danças". Mulheres nas cooperativas de Buenaventura, Guapi e Tumaco expressaram sentimentos semelhantes. Elas queriam manter o enfoque nas atividades produtivas geradoras de renda, 
princípio fundamental da rede era "criar organizações de mulheres autônomas que manifestassem e refletissem nosso desenvolvimento, interesses e identidade étnica e cultural". ${ }^{40}$ CoopMujeres, Ser Mujer e Fundemujer estavam entre as muitas organizações ligadas à Red.

\section{Vendo através dos olhos das mulheres negras: as redes afro-colombianas}

Teofila Betancur é uma guapireña e membro ativo da Red de Mujeres Negras. Durante uma conversa com ela em Cali, em 1995, ela me disse: "As mulheres negras ajudaram a Lei 70 a partir da sua condição de mulher (ser mujer). Contudo, elas têm pouca ou nenhuma participação pública ou políica enquanto mulheres negras. Isso também é verdade nas cooperativas de mulheres negras. As mulheres negras são discriminadas triplamente - enquanto pobres, enquanto mulheres e enquanto negras. Isso as leva a se subvalorizar. As mulheres negras na costa assim como nas cidades estão alisando, pintando ou fazendo permanentes em seus cabelos para ficarem 'brancas' e adotam hábitos da alta sociedade colombiana em uma tentativa de conseguir aceitação social. Isso representa uma perda de valores e de beleza. Então, membros da Rede organizaram oficinas de cabelos e concursos de penteados entre as mulheres negras de Guapi. Agora, mais de metade das guapireñas usam trancinhas, tranças e outros penteados afro-colombianos tradicionais. Precisamos trabalhar a partir da 'cabeça' para recuperar nossa identidade externa como mulheres negras, para refletirmos a respeito e afirmarmo-nos como negras". ${ }^{41}$

Teofila Betancur e suas companheiras acreditam que o enfoque nas identidades e na auto-estima das mulheres negras representa um verdadeiro primeiro passo em direção aos objetivos mais amplos da Red de trabalhar para a melhoria das mulheres negras e suas comunidades. ${ }^{42}$ Quando encontrei Teofila novamente em 1999, ela me disse que a seção da Rede em Guapi agora incluía 74 grupos locais, ribeirinhos e regionais de mulheres, no estado de Cauca. Cada grupo está envolvido em vários tipos de atividades, inclusive projetos 'produtivos' como o cultivo e a recuperação de grãos alimentícios e plantas medicinais nativas, assim como projetos de 'conservação' com foco nas práticas agrícolas e silvícolas para conservar o meio ambiente e a biodiversidade. ${ }^{43}$ De acordo com Teofila, as diversas atividades e projetos empreendidos por grupos dentro da Rede surgem de "suas necessidades, percepções e experiências como mulheres negras, e representam a sua força coletiva". Para simbolizar essa força, a Rede de Guapi adotou o nome Red de Organizaciones Femeninas del 
número um, o amigo-homem" tratava-se de uma alusão não apenas aos homens em casa, como também aos homens inseridos nas lutas mais amplas dos/as negro/as na região. Os membros do Fundemujer afirmam:

Queremos ver as lutas étnico-políticas com os olhos de mulheres negras. Mas o PCN não quer as duas lutas juntas. A opinião deles é que a luta de gênero enfraquece a luta étnica. ${ }^{46}$

Apontando exemplos das muitas mulheres negras que estavam envolvidas no processo de mobilização para a ratificação da AT 55, membros do Fundemujer ecoaram a observação de Teofila de que as mulheres negras e suas organizações desempenharam um papel crucial na luta pela Lei 70. Mercedes, Patrícia, Dora e Myrna observaram também que as mulheres negras ofereceram um apoio logístico importante (cozinhando para o encontro, administrando o escritório, controlando as finanças) dentro do PCN. No entanto, como Teofila, elas sentiram que os membros do PCN não reconheceram nem valorizaram o trabalho e a importância das mulheres negras enquanto mulheres. ${ }^{47}$ De acordo com elas, até as mulheres que têm um papel importante no PCN não possuem uma "consciência de gênero". Patricia Moreno continua:

Armando [do PCN] disse que eles tinham medo que nós falássemos sobre gênero e esquecêssemos a luta étnica. Eles acham que questões de gênero vindas do "interior" [referindo-se às capitais andinas da região e do país] irão diluir a luta étnica. Isso os apavora. Eles acreditam que nós não sentimos a nossa própria opressão. São as forças externas que nos "pesquisam". Como se não sentíssemos nossa subordinação sexual e física!

Os ativistas do PCN contestam tal caracterização de seu posicionamento em relação às mulheres e às questões de gênero. Eles enfatizam que não apenas reconhecem o papel central desempenhado pelas mulheres negras na vida social, cultural e política do Pacífico, como também admitem a necessidade de se abordar questões de gênero dentro do PCN. ${ }^{48}$ Entretanto, reiteram seu posicionamento firme em relação às intervenções do Estado na região, inclusive "a nova política de gênero". Os membros do PCN afirmam que as relações de gênero são relações sociais fundamentais, e que a dinâmica entre homens e mulheres negras são mais bem abordadas através de lutas para se conquistar direitos étnicos e não através de programas estatais direcionados às mulheres. A posição do PCN é a de que as organizações e redes de mulheres negras funcionando de maneira independente dos movimentos étnicos mais amplos da região terminariam sendo 
étnicas e de gênero, para contestar as forças hegemônicas do desenvolvimento apoiado pelo Estado. Abaixo, ofereço uma leitura diferente do ativismo das mulheres negras. Argumento que as subjetividades e atividades das mulheres negras são moldadas através e contra as intervenções políticas e culturais na região.

\section{Através de ser y tener: constituindo etnia, gênero e desenvolvimento no Pacífico}

Ponderando sobre uma política de desenvolvimento para e por mulheres no Pacífico colombiano, Maria Del Rosario Minaescreve:

Temos um interesse básico: trabalhar conjuntamente entre nós mesmas e com outras para propor uma política de desenvolvimento para as mulheres afrodescendentes da região do Pacífico que corresponda à nossa existência básica (SER), a partir da qual seja possível identificar as condições e necessidades materiais e sociais (TENER) que garantam essa existência. ${ }^{49}$

Para Mina, um enfoque nas necessidades materiais não se choca com a recuperação e o orgulho da identidade. Pelo contrário, na sua formulação da "política de desenvolvimento para mulheres negras do Pacífico", 'ser' (existir) e 'tener' (ter as necessidades que garantam essa existência) estão dialeticamente ligados. Para as mulheres negras do Pacífico, participar dos projetos de modernização do Estado não significa apenas abandonar suas identidades e tradições para conquistar aquilo que o desenvolvimento promete. Pelo contrário, para as mulheres negras, engajarse no desenvolvimento significa engajar-se na luta pelo poder de definir o que se entende por 'necessidades' e de criar meios de atendê-las. Isso requer que as mulheres se engajem estrategicamente com o poder estatal e com suas intervenções desenvolvimentistas, assim como com as lutas étnicas. Também requer que recorram ao seu conhecimento das práticas tradicionais e culturais de sobrevivência no Pacífico. Minha discussão sobre o ativismo das mulheres afrocolombianas refere-se a pelo menos duas questões sobre o debate em torno do desenvolvimento: primeiro, as lutas dos grupos locais contra o Estado e a modernização; e, segundo, os problemas do ativismo político e 'agenciamento' das mulheres do Terceiro Mundo. ${ }^{50}$

A década de 1980 presenciou muitos países latinoamericanos enfrentando graves crises financeiras, tumultos políticos e levantes sociais. Estudiosos/as dos novos movimentos sociais (NMSs) na América Latina afirmam que coalizões pouco organizadas de trabalhadores/as de 
alternativas para o desenvolvimento e as literaturas dos NMSs histórica e analiticamente, a fim de argumentar que o desenvolvimento e os movimentos contra ele estão implicados uns nos outros. Afirma que as buscas que vemos hoje por alternativas às forças destrutivas do capitalismo precisam começar a examinar como o moderno e o nãomoderno produzem um ao outro em inúmeros locais.

Minha discussão do ativismo das mulheres negras no Pacífico mostra que gênero desempenha um papel crucial nessa produção e contestação do desenvolvimento. Enquanto os primeiros estudos acerca de gênero e desenvolvimento retratavam as mulheres como vítimas e recipientes passivas das políticas de bem-estar social, estudos feministas recentes revelam a multiplicidade de localidades e de questões em torno das quais uma diversidade de mulheres age. ${ }^{59}$ Feministas pós-coloniais como Chandra Mohanty, Aihwa Ong e Gayatri Spivak ${ }^{60}$ elucidam como estruturas do capitalismo, discursos de desenvolvimento e de gênero, patriarcados locais e noções de cultura constituem as subjetividades das mulheres de maneiras específicas e são utilizados para reforçar certos significados e práticas, e para evitar outros. Essas feministas chamam a atenção para a natureza dinâmica e oposicional da dominação e da resistência das mulheres dentro de relações desiguais de poder. Por exemplo, em Women Workers and Capitalist Scripts, Mohanty ${ }^{61}$ enfoca não apenas a exploração de mulheres trabalhadoras do Terceiro Mundo pela atual expansão capitalista, com também "seu agenciamento enquanto trabalhadoras, em nome dos interesses comuns das mulheres trabalhadoras, baseado na compreensão de localidades e necessidades compartilhadas, e nas estratégias/práticas de organização que estão ancoradas na, e levam à, transformação das vidas cotidianas das mulheres trabalhadoras". ${ }^{62}$ Similarmente, no seu estudo sobre as operárias de fábricas na Malásia, Ong ${ }^{63}$ discute como essas mulheres camponesas que se tornaram assalariadas são moldadas pelas, e resistem às, relações industriais capitalistas.

O exemplo das cooperativas de mulheres negras e da Red de Mujeres Negras destaca como as subjetividades e as organizações afro-colombianas são moldadas pela linguagem e pelas práticas de instituições para o desenvolvimento e suas políticas de gênero atuais. Por sua vez, as mulheres negras utilizam-se dos termos e recursos das iniciativas desenvolvimentistas e dos discursos culturais predominantes na região para abordar as suas necessidades e subverter as agendas tanto do Estado como das lutas étnicas. Através dessa constituição mútua, elas ajudam a institucionalizar as intervenções do Estado e, simultaneamente, 
estados do sudoeste do Pacífico), assim como de representantes de organizações da Costa Atlântica e da capital Bogotá. Grupos do estado de Choco, que fica ao noroeste, preferiram se organizar separadamente.

Minhas discussões sobre o posicionamento e estratégias do PCN baseiam-se em vários encontros e conversas com membros de organizações do PCN durante trabalho de campo na região. Líderes do PCN, como Carlos Rosero, Libia Grueso, Hernan Cortés e Leyla Andréa Arroyo também expressam seus pontos de vista em seminários, conferências e fóruns com vistas a discutir os direitos dos/as negros/as, que são amplamente publicados em minutas ou anais das conferências. Baseio-me nesses pareceres coletados durante o meu trabalho de campo e forneço citações paralelas de fontes publicadas sempre que possível.

${ }^{13}$ Tais críticas ao desenvolvimento são ecoadas largamente por acadêmicos/as e ativistas, no norte e no sul. Por exemplo, os/as vários/ as colaboradores/as do Dicionário do desenvolvimento: um guia para o conhecimento como poder (Wolfgang SACHS, 1992) analisam certos conceitos-chave do desenvolvimento - tais como Planejamento, Pobreza, Produção, Progresso, Padrão de Vida, etc. - em um esforço de expor os limites do pensamento acerca do desenvolvimento e de imaginar uma "era pós-desenvolvimento". Esses/as críticos/as argumentam que, através de alegações enganosas de superioridade dos sistemas econômico e político do Ocidente, os discursos sobre o desenvolvimento constroem um Terceiro Mundo 'subdesenvolvido' e impõem uma 'racionalidade' e conhecimento ocidental a esses espaços.

${ }^{14}$ ROSERO, 1996, p. 182.

${ }^{15}$ Alguns projetos propostos no Plan Pacífico pelo Conselho Nacional de Política Econômica e Social (CONPES) e pelo Departamento Nacional de Planejamento (DNP) da Colômbia incluem: a construção de estradas ligando centros regionais-chave com centros de troca e comércio andinos, construindo oleodutos e usinas hidroelétricas, e construindo e modernizando vários portos. Ver em Diego PIEDRAHÍTA e María Estella PINEDA, 1993, uma lista detalhada e uma descrição das propostas desses projetos. Ver também www.dnp.gov.co para uma visão geral das agendas de desenvolvimento da Colômbia.

${ }^{16}$ Gustavo DE ROUX, 1990-1991; Alvaro PEDROSA, 1996; ROJAS, 1994.

${ }_{17}$ Por exemplo, a pesquisa de Carmen Diana DEERE e Magdalena LEÓN (1981), em três regiões andinas que se desenvolvem com maior rapidez na Colômbia e no Peru, mostrou que o maior envolvimento de mulheres no trabalho agrícola caminha lado a lado com o empobrecimento geral de grandes setores rurais. Ver também seu volume editado Rural Women and State Policy: Feminist Perspectives on Latin American Agricultural Development (DEERE e LEÓN, 1987) para discussões sobre como as políticas agrícolas do Estado afetem as mulheres em várias partes da América Latina e da bacia caribenha.

${ }^{18}$ LOZANO, 1996.

19 GRUESO, 1998; GRUESO et al., 1998.

${ }^{20}$ OCN, 1996; ROSERO, 1995 e 1996.

${ }^{21}$ Julio CARRIZOSA UMANÃ, 1993; Arturo ESCOBAR, 1996; ROJAS, 1994; Juan Pablo RUIZ, 1993.

$22 \mathrm{PCN}, \mathrm{s} / \mathrm{d}, \mathrm{p} .2$.

${ }^{23}$ Como era de se esperar, há debates intensos na Colômbia, inclusive entre negros/as, sobre o que constitui a etnia e a diferença 'afrocolombiana'. Muitas pesquisas têm enfocado a forma como as diferenças culturais e de identidade dos/as negros/as ou afrocolombianos/as são entendidas e construídas pelos movimentos sociais negros depois da Lei 70. Ver ASHER, 1998; Eduardo RESTREPO, 1998 e 2001; e Peter WADE, 1996, para algumas discussões importantes. Ver 
manuscritos publicados e não-publicados sobre e pela rede de mulheres, e de um videoteipe do segundo encontro da rede de mulheres da região de Cauca e Nariño, realizado em Timbiqui, Cauca, no período de 1 a 4 de maio de 1997.

43 Ver ASHER, 2002, para uma análise mais detalhada sobre 0 envolvimento de mulheres negras (inclusive do grupo de Teofila) em projetos de desenvolvimento sustentável e de preservação da biodiversidade, no estado de Cauca, no sudoeste colombiano. Ver Juana CAMACHO, 1999 e 2001, para uma discussão sobre o papel central das mulheres na administração de recursos agrícolas e da biodiversidade, e na manutenção de redes sociais nas áreas costeiras do estado de Choco, no noroeste.

${ }^{44}$ Observação participativa no seminário e na marcha organizada pela Red de Mujeres Chocoanas, no Dia Internacional da Mulher, 8 de março de 1995, e em entrevistas com as organizadoras do evento, Adriana Eliza Fox Porro e Nimia Teresa Cuesta.

${ }^{45}$ Talvez a explicação por que as mulheres da OBAPO resolveram se organizar sob os auspícios de uma organização negra resida no fato de que a maior parte das posições de liderança na OBAPO é de mulheres.

${ }^{46}$ Isso me traz à mente as reflexões de Audre Lorde sobre o movimento negro nos Estados Unidos:

"Dentro das comunidades negras onde o racismo é uma realidade viva, as diferenças entre nós geralmente parecem suspeitas e perigosas. A necessidade de unidade é normalmente mal interpretada como uma necessidade de homogeneidade, e o olhar de uma feminista negra, confundido com traição dos nossos interesses comuns enquanto um povo" (LORDE, 1992, p. 51).

${ }^{47}$ Ver ASHER, 1997, para uma discussão sobre a questão contraditória da presença de mulheres negras como líderes em movimentos sociais negros e a sua invisibilidade enquanto mulheres negras nessas organizações.

${ }^{48}$ OCN, 1996, p. $256-260$.

${ }^{49}$ MINA, 1995.

${ }^{50} \mathrm{O}$ ativismo das mulheres afro-colombianas baseado na ligação entre 'ser' e 'tener' também problematiza a caracterização da luta das mulheres do Terceiro Mundo como sendo ou lutas 'femininas' para atender às 'necessidades práticas' ou lutas 'feministas' pelo poder de redefinir as relações de gênero e contestar as posturas políticas e econômicas do Estado. Ver Marianne MARCHAND, 1995, para uma discussão sobre como essas visões sobre as lutas das mulheres são aplicadas para uma melhor compreensão do ativismo das mulheres.

${ }^{51}$ Susan ECKSTEIN, 1989; David SLATER, 1985; e Arturo ESCOBAR e Sonia ALVAREZ, 1992.

52 A literatura dos NMSs é influenciada em vários níveis pelos debates pós-estruturalistas nas ciências sociais e humanas e textos 'antidesenvolvimento' que surgiram nas décadas de 1980 e 1990. Muitos/as estudiosos/as e ativistas do Terceiro Mundo (ESCOBAR, 1992; SACHS, 1992; e Vandana SHIVA, 1988) denunciam os projetos desenvolvimentistas como um subgrupo da modernidade hegemônica, eurocêntrica. Baseandose em trabalhos recentes em historiografia pós-colonial, eles chamam a atenção para a necessidade de se reconhecer racionalidades 'nãoocidentais'. De acordo com esses/as críticos/as, alternativas às tendências homogeneizantes e excludentes do capitalismo global são encontradas nas práticas tradicionais dos grupos locais.

${ }^{53}$ ESCOBAR e PEDROSA, 1993 e 1996.

${ }^{54}$ Ou para usar a frase de Verónica Schild, questiono a "separação tão definida entre Estado e sociedade civil” (SCHILD, 1998, p. 111), que está implícita em muito da literatura dos NMSs sobre as lutas locais contra o desenvolvimento. Escrevendo sobre o projeto de democratização e 
Ourselves as Women, Rescuing our Black Identity: Ethnicity and Gender in the Pacific Lowlands." Current World Leaders, v. 40, n. 6, 1997. p. 106-127.

"Culture/Politics and Black Ethnicities in the Pacific Coast of Colombia." Paper presented at XXI International Conference of the Latin American Studies Association, Chicago, September 24-26, 1998.

. "Mobilizing the Discourses of Sustainable Economic Development and Biodiversity Conservation in the Pacific Lowlands of Colombia." Strategies: A Journal of Theory, Culture and Politics, v. 13, n. 1, 2000. p. 111-125.

"Texts in Context: Afro-Colombian Women's Activism in the Pacific Lowlands of Colombia." Feminist Review, 2002. Under review.

BALANTA, Olivia; RODRÍGUEZ, Betty; SINISTERRA, Sonia; Quiñonez, Piedad; ARROYO, Leila; EQUIPO DINAMIZADOR. "Red de Mujeres Negras del Pacífico: tejiendo procesos organizativos autonomos". Esteros, n. 9, p. 37-42, feb. 1997.

BRAIDOTTI, Rosi, CHARKIEWICZ, Ewa, HÄUSLER, Sabine, and WIERINGA, Saskia (eds.). Women, the Environment and Sustainable Development: Towards a Theoretical Synthesis. London: Zed Books, 1994.

CAMACHO, Juana. "'Todos tenemos derecho a su parte': derechos de herencia, acceso y control de bienes en comundiades negras de la costa Pacífica chocoana". In: CAMACHO, Juana; RESTREPO, Eduardo (Coords.). De montes, ríos, y ciudades: territorios e identidades de la gente negra en Colombia. Santa Fe de Bogotá: Fundación Natura, Ecofondo, Instituto Colombiano de Antropología, 1999. p. 107-130.

. "Mujeres, zoteas y hormigas arrieras: prácticas de manejo de flora en la costa Pacífica chocoana". In: ARROYO, Jesús; CAMACHO, Juana; LEYTON, Mireya; GONZÁLEZ, Maribel (Coords.). Zoteas: biodiversidad y relaciones culturales en el Chocó biogeográfico colombiano. Bogotá: Instituto de Investigaciones Ambientales del Pacífico-IIAP, Fundación Natura, Fundación Swissaid-Colombia, 2001 . p. 35-58.

CAMACHO, Juana; RESTREPO, Eduardo (Coords.). De montes, ríos, y ciudades: territorios e identidades de la gente negra en Colombia. Santa Fe de Bogotá: Fundación Natura, ECOFONDO, Instituto Colombiano de Antropología, 1999.

CARRIZOSA UMAÑA, Julio. "El Chocó y el resto del mundo." Ecologica: Politica, Medio Ambiente, Cultura, v. 4, n. 1516, p. 12-17, 1993.

COAMA (Consolidación de la Región Amazónica). Los 
.Viejas y nuevas formas de capital y los dilemas de la biodiversidad". In: ESCOBAR, Arturo and PEDROSA, Alvaro (eds.). Pacífico ¿Desarrollo o Diversidad?: Estado, capital y movimientos sociales en el Pacífico colombiano. Bogotá: CEREC y Ecofondo, 1996. p. 109-131.

."Cultural Politics and Biological Diversity: State, Capital, and Social Movements in the Pacific Coast of Colombia." In: LOWE, Lisa, and LLOYD, David (eds.). The Politics of Culture in the Shadow of Capital. Durham, NC: Duke University Press, 1997. p. 201-225.

ESCOBAR, Arturo, and ALVAREZ, Sonia. The Making of Social Movements in Latin America: Identity, Strategy, and Democracy. Boulder, CO: Westview Press, 1992.

ESCOBAR, Arturo; PEDROSA, Alvaro. "¿Laboratorio para el postdesarrollo?" Revista Universidad del Valle, n. 5, p. 34-45, 1993.

ESCOBAR, Arturo; PEDROSA, Alvaro. "Camaroneras comunitarias: ¿Alternativas al capital? Entrevista con Harold Moreno y Relato de Doña Ester Caicedo". In: ESCOBAR, Arturo, and PEDROSA, Alvaro (Coords.). Pacífico ¿Desarrollo o Diversidad?: Estado, capital y movimientos sociales en el Pacífico colombiano. Bogotá: CEREC y Ecofondo, 1996. p. 144-175.

ESTEROS. Mujeres negras e indigenas definiendo futuro, v. 5, n. 9, feb. 1997. Número especial.

FEMPRESS: Red de comunicación alternativa de la mujer. Mujeres negras, Latinoamerica, 1995. Número especial.

FERGUSON, James. The Anti-Politics Machine: "Development", Depoliticization, and Bureaucratic Power in Lesotho. Cambridge, UK: Cambridge University Press, 1990.

GROS, Christian. Colombia indigena: identidad cultural y cambio social. Bogotá, Colombia: CEREC, 1991.

GRUESO, Jesus Alberto; ESCOBAR, Arturo. "Las cooperativas agrarias y la modernización de los agricultores". In: ESCOBAR, Arturo, and PEDROSA, Alvaro (eds.). Pacífico ¿Desarrollo o Diversidad?: Estado, capital y movimientos sociales en el Pacífico colombiano. Bogotá: CEREC y Ecofondo. 1996. p. 90-108.

GRUESO, Libia Rosario. "El ejericio del derecho al territorio en la comunidad negra del Pacífico Sur: un reto en doble vía". Buenaventura, Colombia, 1998. Manuscrito.

GRUESO, Libia, ROSERO, Carlos, and ESCOBAR, Arturo. "The Process of Black Community Organizing in the Southern Pacific Coast Region of Colombia." In: ALVAREZ, Sonia, DAGNINO, Evelina and ESCOBAR, Arturo (eds.). Cultures of Politics/Politics of Cultures: Re-visioning Latin American Social Movements. Boulder, CO: Westview Press, 1998. p. 196-219. 
OCN (Organización de Comunidades Negras). "Movimiento negro, identidad y territorio: entrevista con la Organización de Comunidades Negras de Buenaventura". In: ESCOBAR, Arturo; PEDROSA, Alvaro (Coords.). Pacífico ¿Desarrollo o Diversidad?: Estado, capital y movimientos sociales en el Pacífico colombiano. Bogotá: CEREC y Ecofondo, 1996. p. 245265.

ONG, Aihwa. Spirits of Resistance and Capitalist Discipline: Factory Women in Malaysia. Albany, NY: State University of New York Press, 1987.

.Colonialism and Modernity: Feminist Re-presentations of Women in Non-Western Societies." Inscriptions, v. 3-4, n. 2, 1988. p. 79-93.

PARDO, Mauricio (Coord.). Acción colectiva, Estado y etnicidad en el Pacífico colombiano. Bogotá: ICANH, Colciencias, 2001.

PARDO, Mauricio; ALVAREZ, Manuela. "Estado y movimiento negro en el Pacífico colombiano". In: PARDO, Mauricio (Coord.). Acción colectiva, Estado y etnicidad en el Pacífico colombiano. Bogotá: ICANH, Colciencias, 2001. p. 229-258.

PCN (Proceso de Comunidades Negras). "El Proceso de Comunidades Negras en el centro-sur del Pacífico y el problema del 'desarrollo'”. Buenaventura, Colombia, n.d. Manuscrito.

PEDROSA, Alvaro. "La institucionalizacion del desarrollo". In: ESCOBAR, Arturo; PEDROSA, Alvaro (Coords.). Pacífico ¿Desarrollo o Diversidad?: Estado, capital y movimientos sociales en el Pacífico colombiano. Bogotá: CEREC y Ecofondo, 1996. p. 66-89.

PEET, Richard, and WATTS, Michael (eds.). Liberation Ecologies: Environment, Development, Social Movements. London and New York: Routledge, 1996.

PIEDRAHÍTA, Diego; PINEDA, María Estella. "En vías de desarrollo: lista de proyectos de desarrollo para el Pacífico". Ecologica: Politica, Medio Ambiente, Cultura, v. 4, n. 15-16, 1993. p. 83-86.

RESTREPO, Eduardo. "La construcción de la etnicidad: comunidades negras en Colombia". In: SOTOMAYOR, Maria Lucia (Coord.). Modernidad, identidad y desarrollo: construcción de sociedad y re-creación cultural en contextos de modernización. Bogotá: ICAN, 1998. p. 341-358.

- "Imaginando comunidad negra: etnografía de la etnización de poblaciones negras en el Pacífico sur colombiano". In: PARDO, Mauricio (Coord.). Acción colectiva, Estado y etnicidad en el Pacífico colombiano. Bogotá: ICANH, Colciencias, 2001. p. 41-70. 
TINKER, Irene (ed.). Persistent Inequalities: Women and World Development. Oxford: Oxford University Press, 1990.

VILLA, William. "El Pacífico colombiano: políticas de desarrollo". Esteros, n. 1, p. 15-19, enero/marzo, 1993.

."El plan de desarrollo de comunidades negras en la ley 70 de 1993". Esteros, n. 7, p. 36-40, agosto 1995.

WADE, Peter. "The Language of Race, Place and Nation in Colombia." America Negra, n. 2, 1991. p. 41-68. . Blackness and Race Mixture: The Dynamics of Racial Identity in Colombia. Baltimore and London: The Johns Hopkins Press, 1993.

. "The Cultural Politics of Blackness in Colombia." American Ethnologist, n. 22, v. 2, 1995. p. :341-357. . "Identidad y etnicidad". In: ESCOBAR, Arturo; PEDROSA, Alvaro (Coords.). Pacífico ¿Desarrollo o Diversidad?: Estado, capital y movimientos sociales en el Pacífico colombiano. Bogotá: CEREC y Ecofondo, 1996. p. 283298.

WATTS, Michael. “'A New Deal in Emotions': Theory and Practice and the Crisis of Development." In: CRUSH, Jonathan (ed.). Power of Development. London and NY: Routledge, 1995. p. 44-62.

WESTWOOD, Sallie, and RADCLIFFE, Sarah A. "Gender, Racism and the Politics of Identities in Latin America." In: RADCLIFFE, Sallie A., and WESTWOOD, Sarah (eds.). 'Viva': Women and Popular Protest in Latin America. London and New York: Routledge, 1993. p. 1-29.

Ser y Tener: Engendering Development and Ethnicity in the Pacific Lowlands of Colômbia Abstract: In this paper I explore how Afro-Colombian women's organizations and networks shape and are shaped by state initiatives to develop and modernize the Pacific region. I argue that in doing so these mobilize and go beyond the developmentalist rhetoric of the state and the discourse of gendered black ethnicity and tradition of black political organizations in the region. Key words: Afro-Colombian women, development strategies, gendered ethnicity in politics.

Tradução de Ana Cecília Acioli Revisão da tradução: Susana Bornéo Funck 